\title{
Excessive internet use in the general and ultra-orthodox Jewish communities: Internet addiction or a medium to fuel other addictions?
}

\author{
Rena Kurs ${ }^{* 1}$ and Alexander Grinshpoon ${ }^{1,2}$ \\ ${ }^{1}$ Sha'ar Menashe Mental Health Center, Israel \\ ${ }^{2}$ Rappaport Faculty of Medicine, Technion Israel Institute of Technology, Haifa, Israel
}

\begin{abstract}
In this paper we present the concept of "internet addiction" as opposed to excessive behavior disorders. To illustrate the widespread problem and proposed solutions, we have chosen to focus on the example of the excessive internet use in the Orthodox Jewish Community which is a relatively closed, but international society. The authors present the negative attitudes of the leaders of that community towards internet use in general and then describe problematic internet use both in the general population and specifically in Orthodox Jewish communities.Examples of treatment options for excessive internet use are then provided. In conclusion, the legal implications of future classification of problematic internet use as 'internet addiction' are mentioned, as well as recommendations for guidance and education for responsible utilization of the internet.
\end{abstract}

\section{Introduction}

\section{Benefits of internet use}

Internet use has become widespread worldwide, as it provides high speed access to a global repository of information. Knowledge with high up to date educational and entertainment value is now readily available to the general public regardless of social or economic status [1]. Worldwide expansion of the internet has created job opportunities in the global community and extended the option of working from home. The internet has dramatically re-structured the way business is done, beginning with online shopping, internet banking and e-commerce. E-learning and internet courses have made higher education accessible to broader populations and some college degrees can now be attained via online courses for which students do not need to physically come to the classroom.

In the social domain, online social networking can help people stay in touch, meet new people with similar interests or renew old friendships. However, as an intrinsic, essential and almost unavoidable part of daily life. the ubiquitous use of the internet has also led to some negative phenomena. Research has revealed inappropriate or excessive internet use, especially among the younger generation [2].

We will first present a literature review of the concepts of addiction, behavioral disorders and various concepts describing the broader phenomena of problematic internet use. To illustrate the extent of the impact of the phenomenon we have chosen the Orthodox Jewish Community, which has been described as a closed or "enclave" society. The unique boundaries of this community which would seemingly "protect" its members from this affliction, once crossed, seem to exacerbate the addiction in this society. The very nature of the internet which serves as a window to the world from the privacy of the home may indeed account for proliferation of readily identifiable extreme cases of internet addiction in this society. Once the boundaries have been crossed, however, the addiction and is consequences do not necessarily differ from those in the general community. Thus the treatment options presented, might be applicable to those with similar "addictions" regardless of their religious or ethnic affiliations.

\section{Literature review}

\section{The difference between physiological and behavioral addictions}

In 1995, in an effort to parody the way the American Psychiatric Association seems to medicalize excessive behaviors in the Diagnostic and Statistical Manual of Mental Disorders, psychiatrist Ivan Goldberg introduced the concept of "Internet Addiction Disorder" [3].

In recent years, the term "addiction" has been extended beyond dependence on substances to include non-substance-related behaviors that result in disorders and impairments. Shopping, exercise, gaming, and various types of internet-enabled behaviors such as social media communications, and various forms of sexual behavior have been proposed as "behavioral addictions" [4]. Investigators testing for similarities with the Diagnostic and Statistical Manual of Mental Disorders (American Psychiatric Association, 2013) [5] seem to be following a "me too" approach. In addition, there is a general lack of agreement regarding how excessive behavior syndromes are defined and described [6]. Substance and behavior addictions may seem to effect behavioral patterns, emotions and physiology in a similar manner. Thus gambling disorder has been included alongside substance abuse disorder in the DSM-5 under the heading of "Substance use and addictive disorders" (American Psychiatric Association, 2013)

Correspondence to: Rena Kurs, Medical Library, Sha'ar Menashe Mental Health Center, Mobile Post Hefer 37806, Israel, Tel: +972-4-627-8160; Fax:+972-4-6273158;E-mail: rena@sm.health.gov.il

Received: November 20, 2016; Accepted: December 21, 2016; Published: December 23, 2016 
[5]. However, there remain clear differences between substance use disorders and behavioral addictions, mainly that substances provide, by definition, physiological input beyond what the body can produce through behavior alone. Consequently, substance abuse disorders are characterized by several physically oriented criteria such as tolerance and withdrawal which are criteria not usually present in behavioral addictions. Thus, there is serious debate regarding the similarity of criteria for behavioral and substance addictions and whether the physical criteria of tolerance and withdrawal are applicable to behavior addictions [7].

\section{Internet addiction}

Since the introduction of the term "Internet addiction" in 1995, there have been eighteen years' worth of research, and "internet addiction disorder" has not risen to the level of recognition in the DSM-5 (American Psychiatric Association, 2013) [5], even in the chapter on "Conditions for further study". This is despite the hundreds of peer-reviewed studies published on the subject of "internet addiction" [8]. For example, though internet addiction has not been formally included in DSM-5 as a disorder, it is now an issue that is debated throughout the world. It has been broadly defined as a nonchemical, behavioral addiction, which involves human-machine interaction [9]. Furthermore, throughout the world, many younger individuals have recently developed internet use disorders (IUDs) owing to the proliferation of internet enabled devices, leading to serious physiological and social difficulties. In some countries, medical, educational and governmental institutions, have gone so far as to take preventive action or alternatively to treat internet use disorders [10]. In most cases, prevention is considered the best cure, and the preferred treatment for internet use disorders is to set recommendations for appropriate internet use [10].

However, the phenomenon of "internet addiction" as a psychological disorder continues to be debated and researched in the psychiatric community [7]. Models of internet addiction share some criteria, including feeling a loss of control over internet use; ensuing psychological, social, or professional conflict or problems; and preoccupation when not using the internet. There is however a consensus that the overuse of the internet can produce a qualitative shift to a diseased state in humans however the current evidence base is not strong enough to provide support for an internet addiction disorder [7].

There are many diverse online stimuli that users could be addicted to aside from the internet per se, e.g. gaming, shopping, cyber-relations and anonymity, and so it is argued that users just use the internet excessively as a medium to fuel other addictions [11]. Incessant checking of emails, texting, tweeting, and surfing the web may serve as pacifiers for the unstable individual by distracting him or herself from daily worries and providing temporary comfort from such concerns [12]. The terms currently used for excessive internet use that interferes with daily life avoid the word addiction and include: problematic internet use (PIU) [13] or pathological internet use (PIU) or compulsive internet use (CIU) [14]. Other overlapping terms include internet overuse, problematic computer use, and even iDisorder $[15,16]$ and internet use disorder (IUD, [10]).

\section{Specific problematic usage of the internet}

\section{Compulsive behaviors: 'cybersex' and 'cyber relationships'}

Opponents to the concept of internet addiction note that compulsive behaviors may not necessarily be addictive [8]. The addiction to 'cybersex', 'cyber relationships', 'net compulsions', 'information and research' and 'computer gaming' are categories that relate to the 'broad' term internet addiction [17]. The addictive stimulus associated with an 'internet addiction' is technically a rewarding and reinforcing stimulus that is transmitted through the internet, as opposed to exposure or access to the internet itself, hence, "Internet addiction" has been considered a misnomer.

Cyber-Relationships have been defined as a virtual connection between two people who have met online, rather than in person, and in many cases interact only via the internet [18]. Addiction to cyberrelationships is an impulse-control problem that has been considered a form of "internet addiction". It has been described as the addiction to social networking such as Facebook, online dating services and chat rooms, creating a place to communicate with new people. Virtual online friends start to gain more communication and importance than real-life family and friends [19]. People suffering from social anxiety or issues regarding shame and guilt may be drawn to internet relationships because in cyberspace they are not seen and can therefore avoid the issue of physical appearance. Without the distraction of face to face realities, they feel they can connect more directly to the mind and soul of the other person [20].

Cyber-Relationships often become more intense than real-life relationships, and they can become addictive. With the option of creating new personas, people can easily deceive the person they are communicating with. Those who enter cyber-relationships are often looking for the perfect companion but the perfect online-companion does not necessarily exist in real life. Two people might commit to a cyber-relationship; however, they might not be the people that they claim to be.

Griffiths [21] has argued that many of these excessive users are not "Internet addicts" but rather use the internet excessively as a medium to fuel other addictions. Griffiths argued that a gambling addict, sex addict or a computer game addict is not addicted to the internet, rather the internet is the medium that enables engagement in the behavior. However, there are reports of individuals who seem to be addicted to the internet itself. These are usually people who use Internet chat rooms or engage in activities (such as sex related activities) that they would not otherwise engage in. These people are often in cyber-relationships and take on other personas and social identities as a way of making themselves feel good about themselves. In these cases, the internet may provide an alternative reality to the user who then becomes immersed in anonymity. The adoption of the new persona may be psychologically and/or physiologically rewarding. The anonymity of the internet has been identified as a consistent factor underlying its excessive use $[22,23]$. This is perhaps particularly relevant to those using internet pornography, which eliminates the embarrassment of going into sex shops. Anonymity may also encourage deviant, deceptive behaviors, some of which are considered illegal and/or amoral. Many, such as sexual deviance, child pornography, sex rings, cyberstalking, sexual solicitation, self-harm groups, and hate groups, are considered both [24].

Probably one of the most unexpected uses surrounding the growth of the internet concerns the development of online relationships and their potentially addicting nature. For some, the primary reinforcement to engage in an online affair and/or cybersex is the sexual gratification they experience online. However, the experience of an online relationship itself, may be reinforced through a subjectively and/or objectively experienced "high." The mood-modifying experience has the potential to provide an emotional or mental escape and further serves to reinforce the behavior. Excessive involvement in this escapist 
activity may lead to addiction [25]. While sexual fulfillment may provide either the initial or subsequent reinforcement, the more potent reinforcement is the ability to cultivate a subjective fantasy world. Online romantic and/or sexual behavior can provide a potent escape from the stresses and strains of real life. These activities fall on what Cooper, Putnam, Planchon, and Boies [26] describe as a continuum from life-enhancing to pathological and addictive.

\section{Problematic/pathological internet use}

Problematic/pathological internet use (PIU) is addictive behavior with fixations, desires, or actions regarding internet access that may lead to harm or anguish. It has been hypothesized that individuals with PIU prefer online interaction to face-to-face encounters. Social interaction plays an important role when evaluating time spent on line, as it can develop negative consequences. Caplan and High [27] found that lonely and depressed individuals may develop a preference for online social interaction, which may lead to negative outcomes with the overuse of the internet that ultimately leads to unfortunate life consequences. As explained by Caplan, the term problematic refers to usage reflecting a specific cycle of innate dysfunction leading to internet use which in turn exacerbates the dysfunction.

The internet is now often an integral part of our daily lives, as we use it for work, to have fun, to shop, and to communicate. Thus, Young's model that compares the internet with drug abuse does not sufficiently explain the current diverseness of this behavior. Unlike drug addiction, the internet can be used beneficially and it has become an inherent component of daily life. Moreover, there is currently no definitive criteria to determine the pathological versus non-pathological use of the internet. According to Musetti et al., internet-related behaviors should assume independent identities and internet use per se, should be considered a normal tool that we need to use to survive but which can be utilized in several pathological ways [28].

In contrast to Musetti who emphasized that appropriate internet use is necessary to survive in today's world, in the Ultra-Orthodox Jewish Community, use of the internet was basically condemned and outlawed, as a potential temptation that could lead to "impure" and pathological behavior. In order to preserve the social norms and isolation of the Ultra-Orthodox Jewish communities, the rabbinic leadership banned use of the internet among its members. However, that very isolation may have prompted the curiosity of members of that community to taste the forbidden fruit. We sought to examine the phenomenon of pathological internet use in this subculture, which was compounded by the guilt associated with transgression of the edicts of religious authority.

\section{Internet interaction as a remedy for the social isolation in enclave cultures}

Internet interaction and cyber-relationships as described above could putatively mollify the social isolation that might be experienced in closed societies such as Ultra-Orthodox communities which are totally segregated communities that zealously preserve their traditional ways of life and distance themselves from the surrounding society [29]. Segregation from the majority society turns the Ultra-Orthodox into an "enclave culture" [30]. Women are further marginalized within the ultra-Orthodox community where key community positions are reserved for men, leaving women in the periphery, idealizing the woman's place in the private sphere [31]. Men, too are in a totally segregated environment.

By contrast, in the internet there are no boundaries of geography, class, nationality or gender. The internet opens up a whole new sphere of relationship-forming. As mentioned previously, the whole process is also disinhibiting. People readily open up emotionally on the internet as it is less threatening than a letter, phone call, or face-to-face encounter. Online relationships and affairs are anonymous, disinhibiting, easily accessible/convenient, affordable, and escape friendly, and thus may account for online infidelity. These very characteristics, make it easy for both men and women in closed societies to dare to take the leap into the outside world without leaving the physical confines of their secluded communities.

As Griffiths [32] pointed out, the structural characteristics of particular activities that are responsible for reinforcement, may satisfy users' needs and may actually facilitate excessiveness.

\section{Internet-controversial technology in Orthodox Judaism}

Over the past 15 years, the internet has been consistently depicted as a controversial technology within Orthodox Judaism, especially by Israeli Ultra-Orthodox rabbis who have issued public edicts regarding its use and who have even banned the internet from their communities [33]. The Israeli Belz Hasidic sect were the first to ban the internet, followed by Israel's Ashkenazi Council of Torah Sages, representing key leaders of notable Ultra-Orthodox communities [33]. The Internet was described as a communal threat and danger to the Jewish people, especially because the web provides easy access to pornography sites and is therefore a potential source for transgression. Ultra-Orthodox rabbis in Israel urged the Jewish community around the world to recognize and embrace this ban [34].

In July 2008, the Belz Hassidic court, which initiated the first official ban, issued a statement allowing community members to use the internet for work-related purposes, although there was a debate surrounding the limits of this permission [35]. This use, however, was contingent upon members using a 'restricted Internet' provided by an Israeli internet company called Internet Rimon, which developed a number of filtering programs for the Haredi community that sought to offer a 'kosher Internet' option, thus blocking content not preapproved by community leaders.

The internet creates possibilities and perils for religious communities and authorities, yet many of these challenges are not new. With the rise of each form of mass media - from the printing press through the birth of electronic media such as radio and television Orthodox Jews have had to weigh the benefits of the new media against the potential conflicts of affiliation with the secular world.

On May 20, 2012, Ultra-Orthodox Jews held a huge rally in Lakewood, New Jersey where the widespread communal awareness of the dangers of the internet was connected to a larger struggle faced by the Jewish people in a secular world. Organizers of the rally claim that pornography is not the only virtual menace. As the New York Times explained: Speakers at the rally in Queens did not seek to ban the Internet, but rather to raise awareness about how, unmonitored, it poses a grave risk to the community. The risk comes not only from pornography, but also from social media and the addictive pull of the internet, which can limit human interaction, reading and study. The rally's organizers clearly think the Internet is one of the biggest threats to traditional Jewish life -- if not the biggest. (Ultra-Orthodox Jews To Hold Huge Rally Against The Internet At Citi Field).

\section{Dilemma of an Orthodox computer technician}

In an online article that appeared on the Jewish Telegraphic Agency website [36], the author described the dilemma of Josh, a 
Brooklyn computer technician who deals almost exclusively with a Haredi Orthodox clientele. Josh encountered a routine situation: A man brought his computer to be cleaned of a virus that Josh believed was acquired while visiting a pornographic website. A few weeks later the man returned with the same problem. Should Josh (not his real name) advise his client about which sites will give him the rush he's after without harming his computer? In Brooklyn's ultra-Orthodox Jewish community, it was a serious moral dilemma. Josh feared for his business reputation; his client was frustrated by the recurring problem. Josh consulted several rabbis, and none agreed that he advise his client on where to find virus-free porn. And though in subsequent years he has encountered the problem numerous times, Josh continued to uphold the rabbish decision." I know the virus when I see it. I know they got it from pornography," said Josh. "When they come back two to three weeks later with the same virus, it's pretty clear they have a problem" [36]. In the Orthodox world, the ready availability of internet pornography is a manifestation of a broader challenge: How to cope with a technology that is becoming increasingly necessary for carrying out an ever expanding universe of daily tasks but offers limitless possibilities for religiously inappropriate behavior.

\section{Problems with internet access in the orthodox Jewish community}

The council of rabbinical authorities, which is the supreme rabbinical policy-making council of several related prestigious Ultra-Orthodox Jewish intra national organizations and routinely issues edicts on Orthodox religious life, repeatedly has urged Jews not to have Internet access at all. And if that proves unavoidable for business reasons, the council has mandated the installation of filters that block the most objectionable materials. Such injunctions appear to be only marginally effective.

\section{Limiting access to the internet}

Aside from the Orthodox Jewish Community, the number of organizations and other communities that limit access to Internet content has rapidly increased in recent years. Compelling arguments for extensive filtering and censorship of the internet include "securing intellectual property rights," "protecting national security," "preserving cultural norms and religious values," and "shielding children from pornography and exploitation,". Many others have debated the enactment of similar measures and have pursued technological solutions to complex sociological issues. There is a host of available internet censorship software available to limit access to approved websites, such as Cyber Patrol Filtering Software, CleanNet, McAfee Office (Guard Dog), American Family Filter, and more.

For example, Microsystems Software, Inc. produces the Cyber Patrol computer program. According to their home page: "Sites to be blocked are selected by a team of parents and teachers hired by Microsystems to surf the Web using state-of-the-art technology to find sexually explicit, violent or hateful material." They maintain a list of banned sites including those which promote drugs (alcohol, tobacco, other drugs), supply militant-terrorist information, information on sex, pornography, nudity or violence [37].

\section{Proposed treatment of internet related problems in the orthodox Jewish community}

The Guard Your Eyes organization and website is one of the leading Orthodox resources for dealing with the prevention and treatment of internet related problems.
Guard Your Eyes has helped prevent thousands from falling into the pitfalls of excessive internet use by providing comprehensive filter services, daily classes and support e-mails on "guarding your eyes", by boosting awareness of the dangers and giving practical tools on how to avoid these tests. They also have a team of certified computer technicians who offer free help for anyone who wants advice or handson assistance with installing filters. Other internet addiction resources for Orthodox Jews include Retorno, Internet addiction resources for the general population include HealthyPlace and MentalHelp.net.

\section{Perceived addiction to internet pornography $v s$ actual use of pornographic websites in religious communities}

Perceived addiction to Internet pornography is increasingly a focus of empirical attention. Grubbs et al., [38] examined the role that religious belief and moral disapproval of pornography use play in the experience of perceived addiction to Internet pornography. Results from two studies in undergraduate samples (Study 1, $\mathrm{N}=331$; Study $2, \mathrm{~N}=97$ ) indicated that there was a robust positive relationship between religiosity and perceived addiction to pornography and that this relationship was mediated by moral disapproval of pornography use. These results persisted even when controlling for actual use of pornography. Although religiosity was negatively predictive of acknowledging use of pornography, religiosity was not related to actual levels of use. A structural equation model from a web-based sample of adults (Study 3, N = 208) revealed similar results. Specifically, religiosity was robustly predictive of perceived addiction, even when relevant covariates (e.g., trait self-control, socially desirable responding, neuroticism, use of pornography) were held constant. The authors concluded that religiosity and moral disapproval of pornography use were robust predictors of perceived addiction to Internet pornography but were not related to actual levels of use among pornography consumers [38].

\section{Conclusion and recommendations}

If the American Psychiatric Association does ultimately include excessive Internet in to the Diagnostic and Statistical Manual of Mental Disorders, the consequences will be wide-ranging. Health insurance companies will need to offer at least partial coverage for treatment programs for coping with "internet addiction". People who suffer from internet addiction disorder will be protected under the Americans with Disabilities Act if their impairment "substantially limits one or more major life activities." Criminal lawyers will use their clients' online habits for diminished capacity defenses [3].

That which began as a parody in 1995 could eventually become more serious than ever imagined. Could health care systems go bankrupt because insurers have to pay for millions of people determined to kick their Twitter addictions? Employees who surf pornography sites at work may be legally protected from termination. Addicted gamers who kill elves in cyberspace could be absolved for killing people in real life! [3].

It is almost impossible to imagine life today without E-commerce, E-banking, E-learning, and vast resources of knowledge at our fingertips. However, alongside these benefits of the internet, misuse or carrying internet use to the extreme remains a potential danger. Though initially, the Ultra-Orthodox Jewish Community totally banned internet use, the restrictions have been eased when internet access is necessary for work related purposes [35], albeit with the stipulation that access uses filters to exclude inappropriate websites. Even so, excessive internet use permeated that community as well, and exemplified the extent of the phenomenon of internet addiction, even in societies that aim to shield their members from external influences. 
Though to date there is no consensus as to the conceptualization of a defined Internet Addiction Disorder [28], whether in ultra-orthodox religious communities or in the general population, the distinction between excessive behaviors and bona fide addictions has serious legal implications. Whether or not a diagnosis has been conceptualized, the problem of excessive internet use has been addressed world over [10].

Considering that the internet is here to stay, the time has come for psycho-education regarding prevention of excessive use of the internet. For example, guidance regarding time management, identification of triggers of problematic internet use, and promotion of functional internet use should accompany explanations and guides for novice internet uses [39].

Education regarding appropriate internet use should begin as soon as young children are exposed to the internet. Rather than banning internet use, community leaders and teachers should help new users learn to differentiate between acceptable and non-acceptable internet use. Guidance should address the hazards of access to inappropriate material, and the safety versus the perils of digital communication. Strict policy should be implemented, that defines the responsibilities of users regarding illegal and/or inappropriate surfing, and protection of personal information [40].

Rather than banning use, children and/or members of enclave societies should be empowered and learn to distinguish beneficial from harmful or menacing materials and to avoid excessive or "addictive" use. Internet education should include guidance regarding how to avoid inadvertent entry to inappropriate material and how to respond if such material was accidentally accessed. Safety concerns regarding sexual predators, excessive use, breach of privacy and internet fraud should be addressed. The best cure to what might or might not be a bona fide diagnosis of addiction is prevention, and education towards safe and responsible use of the internet.

\section{References}

1. Bergmark KH, Bergmark A, Findahl O (2011) Extensive internet involvement--addiction or emerging lifestyle? Int J Environ Res Public Health 8: 4488-4501. [Crossref]

2. Lo MF, Ng A, Fong B, Ho WT (2015) Healthy use of internet and personal knowledge management in knowledge-based economy and tertiary education (Working Paper Series No. 2, Issue 3). The Hong Kong Polytechnic University.

3. Beato $\mathrm{G}(2010)$ Internet addiction.

4. Grant JE, Potenza MN, Weinstein A, Gorelick DA (2010) Introduction to behavioral addictions. Am J Drug Alcohol Abuse 36: 233-241. [Crossref]

5. Zelazny K, Simms LJ (2015) Confirmatory factor analyses of DSM-5 posttraumatic stress disorder symptoms in psychiatric samples differing in Criterion A status. $J$ Anxiety Disord 34: 15-23. [Crossref]

6. Mudry TE, Hodgins DC, El-Guebaly N, Wild TC, Colman I, et al. (2011) Conceptualizing excessive behaviour syndromes: A systematic review. Curr Psychiatry Rev 7: 138-151.

7. Van Rooij AJ, Prause N (2014) A critical review of "Internet addiction" criteria with suggestions for the future. $J$ Behav Addict 3: 203-213. [Crossref]

8. Grohol JM (2013) Not in the DSM-5: Internet Addiction \& Parental Alienation Disorder.

9. Cerniglia L, Zoratto F, Cimino S, Laviola G, Ammaniti M, et al. (2016) Internet Addiction in adolescence: Neurobiological, psychosocial and clinical issues. Neurosci Biobehav Rev 16.

10. Nakayama H, Mihara S, Higuchi S (2016) Treatment and risk factors of Internet use disorders. Psychiatry Clin Neurosci. [Crossref]

11. Griffiths M (2000) Excessive Internet Use: Implications for Sexual Behavior. Cyberpsychol Behav 3: 537-552.

12. Freeman S (2015) Constantly checking your mobile? Then you could be depressed, study claims.
13. Moreno MA, Jelenchick LA, Christakis DA. (2013) Problematic internet use among older adolescents: A conceptual framework. Comput Human Behav 29: 1879-1887.

14. Meerkerk GJ, Van Den Eijnden RJ, Vermulst AA, Garretsen HF (2009) The Compulsive Internet Use Scale (CIUS): some psychometric properties. Cyberpsychol Behav 12: 1-6. [Crossref]

15. Byun S, Ruffini C, Mills JE, Douglas AC, Niang M, et al. (2009) Internet addiction: metasynthesis of 1996-2006 quantitative research. Cyberpsychol Behav 12: 203-207.

16. Rosen LD (2012) iDisorder: Understanding Our Obsession with Technology and Overcoming Its Hold On Us. New York: Palgrave Macmillan.

17. Widyanto L, Griffiths M (2006) 'Internet Addiction': A Critical Review. Springer Science + Business Media Inc. p. 32

18. Vera D (2011) What is a cyber relationship. Uncategorized, March 16, 2011.

19. Saisan J, Smith M, Robinson L, Segal J (2014) Internet and computer addiction: Signs, symptoms, and treatment. Am J Drug Alcohol Abuse 36: 233-241.

20. Suler J (2004) The psychology of text relationships. In: Ron Kraus, Jason S. Zack, George Stricker, (Eds). Online counseling: A handbook for mental health professionals, Elsevier Academic Press, Amsterdam. p. 19-50.

21. Griffiths MD (1999) Internet addiction: Internet fuels other addictions. Student BMJ 7: 428-429.

22. Griffiths MD (1995) Netties anonymous: are some people addicted to the Internet? Times Higher Educational. April 7 Supplement, p. 17.

23. Young K (1998) Internet addiction: The emergence of a new clinical disorder. Cyber Psychol Behav 1: 237-244.

24. McDonald HS, Horstmann N, Strom KJ, Pope MW (2009) The impact of the internet on deviant behavior and deviant communities. Literature Review. Institute for Homeland Security solutions.

25. Griffiths MD (1998) Internet addiction: Does it re- ally exist? In: Gackenbach J (ed.) Psychology and the Internet: Intrapersonal, interpersonal and transpersonal applications. New York, Academic Press, pp. 61-75.

26. Cooper A, Scherer C, Boies SC, Gordon B (1999) Sexuality on the internet: From sexual exploration to pathological expression. Prof Psychol Res Pr 30: 154-164.

27. Caplan SE, High A (2006) Beyond excessive use: The interaction between cognitive and behavioral symptoms of problematic internet use. Communication Research Reports 23: 265-271.

28. Musetti A, Cattivelli R, Giacobbi M, Zuglian P, Ceccarini M, et al. (2016) Challenges in Internet Addiction Disorder: Is a Diagnosis Feasible or Not? Front Psychol 7: 842 [Crossref]

29. Orb MP (1998) Constructing co-cultural theory: An explication of culture, power, and communication. Thousand Oaks, Calif. Sage, USA.

30. Sivan E (1991) "Enclave culture" Alpayim. 4 p. 45-98.

31. El-Or T (1997) Visibility and possibilities: Ultra-Orthodox Jewish women between the domestic and public spheres. Womens Stud Int Forum 20: 665-673.

32. Griffiths MD (1993) Fruit machine gambling: the importance of structural characteristics. J Gambl Stud 9: 133-152.

33. Campbell H (2011) Religion and the Internet in the Israeli Orthodox context. Israe Affairs 17: 364-383.

34. Campbell HA (2010) Chapter One, Religious communities and the internet, Section: Judaism and the internet. When Religion Meets New Media. Routledge, New York.

35. Rotem T (2008) For first time, Hasidic sect approves limited internet use. Haaretz Online.

36. Harris B (2011) Orthodox grapple with ubiquity of internet. Jewish Telegraphic Agency.

37. Robinson BA (2004) Internet censorship software programs. Ontario Consultants on Religious Tolerance.

38. Grubbs JB, Exline JJ, Pargament KI, Hook JN, Carlisle RD (2015) Transgression as addiction: religiosity and moral disapproval as predictors of perceived addiction to pornography. Arch Sex Behav 44: 125-136. [Crossref]

39. Kuss DJ, Lopez-Fernandez O (2016) Internet addiction and problematic Internet use: A systematic review of clinical research. World J Psychiatry 6: 143-176. [Crossref]

40. Willard N (2002) Safe and responsible use of the internet: A guide for educators.

Copyright: (C2017 Kurs R. This is an open-access article distributed under the terms of the Creative Commons Attribution License, which permits unrestricted use, distribution, and reproduction in any medium, provided the original author and source are credited. 